\title{
Capstone Design Projects at the Department of Mechanical and Industrial Engineering at Concordia University
}

\author{
Hong H., Hoa S.V., Bhuiyan N., Siddiqui K. and Pugh M. \\ Department of Mechanical and Industrial Engineering \\ Concordia University \\ Montreal, Quebec, Canada H3G 1 M8 \\ henhong@vax2.concordia.ca,hoasuon@vax2.concordia.ca,bhuiyan@alcor.concordia.ca \\ siddiqui@encs.concordia.ca,pugh@encs.concordia.ca
}

\begin{abstract}
A new approach to conducting the capstone design project at the Department of Mechanical and Industrial Engineering at Concordia University has yielded significantly enhanced student learning experiences. The design, manufacture and test phases of the mechanical engineering projects, and the design, implementation, and test phases for the industrial engineering projects, provided students the opportunity to 'practice their engineering profession' and to instil technical and personal confidence through 'hands-on' realization and achievement of their project goals. This paper describes the new approach and the benefits that resulted.
\end{abstract}

\section{Introduction}

The Capstone Design Course at Concordia University's Mechanical and Industrial Engineering Department is a supervised design, simulation or experimental project. Since 2000, the full-year (twosemester) capstone design project course has become mandatory for all undergraduate students in the Mechanical Engineering (ME) and Industrial Engineering (IE) programs. There are approximately 100 students registered in the ME program and about 20 in the IE program. Students are required to carry out an open-ended design project by putting into practice different elements of science and engineering that they have learned in the previous three years of their undergraduate program. Apart from the openended nature of the projects, students must work in teams which provide them the opportunity to experience and develop their leadership and interpersonal skills, not just amongst team members but also with university technical staff and industry representatives. Each team is also assigned a project supervisor. In addition, the project deliverables include two presentations and the submission of reports at different checkpoints of the course so that students can develop, practice and enhance their oral presentation and scientific writing skills. Each project is allowed a budget of $\$ 500$ for the purchase of materials, supplies, and manufacturing.

\section{Capstone Course Deliverables}

Students are required to follow a well-defined product development process. To guide them in their work, they are required to make use of the textbook, Tools and Tactics of Design [1]. In what follows, the various project phases and milestones/deliverables are described.

\section{Project Concept Phase}

For each academic year from 2000 until 2004, during the first lecture of the Capstone Design course in September, the students were instructed to form teams and define their own projects. Once the teams were formed, they were required to first submit a letter of intent defining their project and stating their objectives and performance expectations from their design. When the projects had been approved by the course coordinators, the teams had to submit a detailed project proposal which included a preliminary conceptual design with constraints and alternative designs, and a cost analysis for hardware and/or software showing that the project was feasible within the budget and schedule constraints. The teams were also encouraged to get industrial sponsorships in the form of hardware and/or monetary donations to improve their budget. Based on the detailed project proposal, the course coordinators determine whether 
the project could be realized within the course time frame. For ME projects, the coordinators also ascertain that the prototype could be built (or implemented) and tested. In cases where projects were deemed infeasible, the students were required to select another project or modify the current one.

\section{Project Design Phase}

During the design phase, teams were required to conduct engineering analysis and system simulation to determine the design parameters and to demonstrate that their design will function according to the performance specifications. During the final design stage, the teams had to produce detailed part/assembly drawings (for ME teams) or detailed process/layout/ system drawings (for the IE teams), in consultation with their project supervisors. The ME teams who wanted their designed components fabricated at the Department Machine Shop had to validate the drawing with the Machine Shop staff during the design stage. Working in conjunction with the machine shop was encouraged in order to practice 'concurrent engineering' to increase manufacturability and to minimize manufacturing and design changes from the design errors. To ensure that the machine shop could properly schedule its work, teams were given deadlines to submit their final drawings.

\section{Project Manufacturing/Implementation Phase}

During the manufacturing phase, ME teams were required to make frequent contact with the machine shop staff to learn how and when their parts were being manufactured and what machining processes were required. For some students who had machine shop experience, they were allowed to manufacture some or all of their parts under the supervision of the machine shop staff. The students with CAD/CAM knowledge could produce CNC G-codes for the machinist. All design drawings had to be finalized and submitted by the end of January for machine shop manufacturing, otherwise the students had to find resources outside the University for their production, or the designs would not be produced. Industrial engineering teams were required to implement their designs physically where applicable (for example, in the case of implementing a new or improved process), or using simulation or analytical methods (for example, in the case of large systems where physical implementation was not feasible).

\section{Project Test Phase}

For the third and final phase of the project, the students validated their designs by testing the manufactured or virtual prototypes. Depending on how well the prototype functioned with respect to expec- tations, the design, manufacture (or implementation) and testing phases should have been repeated at least once, and in best cases, several times. Since the capstone course is limited by time and machine shop resource constraints, this design iteration process was usually limited to the requirement of at least one cycle.

\section{Administrative Tasks}

In addition to the deliverables described above, throughout the project, each student kept a logbook of their work to track and record the progress of their individual and team designs and thoughts, and as a diary of their meetings and project expectations. They were also required to submit progress reports from time to time, as scheduled, to inform course coordinators and supervisors of their work to date and work to be done. Midterm and final presentations were also mandatory.

\section{Comments on the Course}

Usually, about $20 \%$ of the ME students had well defined projects within the first two months from the beginning of the course. These were typically students who had some hands-on experience, and they were usually involved in practical projects such as those from the Society of Automotive Engineers (SAE). The other $80 \%$ of the students usually had difficulty finding good projects, but eventually, all students found some project to work on. However in many cases, various problems were encountered, which are described as follows:

- Projects became paper designs. This was due to the fact that these were designs that could not be finished by the teams within the course time frame, and as a result the University or outside machine shop could not manufacture the hardware prototypes. While the scope of such projects were well-defined at the start of the term, students tended to delay their work until the second term since there were no major deliverables in the first term.

- $\quad$ Projects became unrealistically difficult such that they could not be finished by the end of the course. Although each team had a faculty member as a project supervisor, the supervisor provides advice and guidance, but this does not necessarily mean that the teams followed the suggestions. For such situations, it was difficult to penalize the students since the project was approved by the course coordinator in the early part of the course.

- Industry-related projects that depended on the company to provide facilities for testing usually 
faced several hurdles. Companies are usually busy with their production schedule and may not give priority to the student projects. As a result, a few of these projects were always incomplete by the end of the course. These teams would then request extensions, which would be denied because this would result in unfairness for the other teams who met their deadlines. Furthermore, such projects were also subject to nondisclosure agreements. As a result, students had to present their work in closed sessions to the course coordinators, which prevented others students in the class from sharing all the teams' projects.

- Students sometimes chose SAE projects as their capstone design projects. SAE projects are excellent for the hands-on educational experience of the students since they provide practical objectives to meet and hardware to work on. They also require teamwork and the pressure of having a working prototype to meet competition deadlines. However, more often than not, SAE projects involve the refining of a particular part of the vehicle for the sake of the competition and the open-ended element may not be sufficient. Also the deadline for competition is usually in May, which is about one month after the end of the course. Students invariably asked for the extension of the Capstone project submission deadline to coincide with the deadline of the SAE competition. If the school places a lot of significance in helping the students to win the competition to get publicity, then the deadline of the course may be relaxed to accommodate the students' schedule. This may not be fair to the rest of the students in the course and in some way the academic activity is taken hostage by an external body.

- In terms of the budget, some student projects required relatively large amount of money as compared to the others. It was usually dependent on the purchases required and how much outside work was contracted. This again does not reflect well on the planning for the conduct of the course.

Definitely, the above shortcomings need to be rectified if the students are to be provided with good exposure to design in the form of a capstone design project. In addition, if students do not have good projects to work on, they miss an opportunity for their training. This results in a waste of excellent, young, inquiring minds with innovative solutions that could have been applied to a well-defined problem.

\section{A New Approach to the Capstone Design Course}

In order to address the above shortcomings, the Capstone Design Committee (CDC) in the Department made an effort to find a new approach to plan, organize and manage the course. The CDC is comprised of the ME and IE Capstone coordinators, the Department Chair, select number of faculty members having an interest in design projects, and members from the technical and support staff who are involved in the Capstone projects. One alternative to the problem was to consider obtaining all projects from industry. This requires significant effort on the part of the course coordinators to contact industry for projects, and must be done on a continuous basis. However, there is no guarantee that a sufficient number of good projects can be found. Furthermore, for the reasons stated earlier, students would be reliant on the company constraints. Some controlled way needed to be found to provide a supplement to the good projects proposed by industry or by the students.

\section{Project Planning}

The CDC decided that instead of relying on students to find their own projects, the CDC would select the projects for the majority of the teams, leaving an option open to excellent projects proposed by students or from industry. The CDC also decided that instead of providing a unique project to each team, which could result in 40 to 50 different projects, one or two products would be selected for the students to work on. The job of the students would be to redesign and improve the proposed products. The product must be selected in a way that it should be readily available to the students so that they have ample opportunities to study the existing design. For the academic year 20042005, the CDC decided to select the following two products: a commercially available scooter and a mini hydroelectric unit that may be powered using the flow of a river (for potential use for example, by the population in developing countries). Purchasing four scooters at approximately $\$ 700 \mathrm{CND}$ per unit was not too expensive for the budget of the Department. The hydroelectric unit was the result of an idea from a previous project. Based on these two products, the CDC defined $80 \%$ of the capstone projects (where a number of projects were defined for each product), and left $20 \%$ of the projects up to the students. For the remaining $20 \%$, students were given the option of proposing their own ideas, or industry-related projects. For these projects, the students were advised to submit a letter of intent. The CDC reviewed and approved the promising, feasible projects. 
The CDC began working on defining the scooter and hydroelectric projects in May 2004. They defined the subprojects for the scooter, and performed some analysis to make sure that the two projects could be finished within the time frame of the course. If there were some general or specific equipment necessary, such as scooters, methane tanks for the $\mathrm{CNG}$, electric generators for the hydroelectric unit, high pressure fittings and hoses, and hand-tools, these were acquired in the summer of 2004 before the beginning of the course. Also, to ensure that the teams can test their designs without any interference with the scheduled course laboratories during the teaching semesters, special arrangements were made during the summer. These included arrangements with the Civil Engineering Department for access to their water resources lab for the hydroelectric project, access to the materials testing machines, the modification and preparation of the engine dynamometer, and consultation with the university Health and Safety Office on matters such as the safe use of compressed methane.

\section{Scooter Projects}

The original idea for the scooter project was to develop a hybrid-electric regenerative-braking, alternative fuel, lightweight vehicle. There would be three teams working on each scooter. One team would work on selecting and converting a smaller 2-stroke or 4-stroke gasoline engine into a compressed natural gas $(\mathrm{CNG})$ engine to reduce exhaust pollution and fuel consumption. A second team would work on the motor/generator electric battery driving system capable of regenerative braking to supplement the power needed for the smaller $\mathrm{CNG}$ engine during acceleration. The third team would work on modifying the scooter chassis with lightweight materials to further reduce fuel consumption, to study the scooter dynamics and handling due to modifications from the first two teams, and to study the effects of the energy absorbing crumple zone to protect the driver during a frontal impact. The three teams would work together to produce the hybrid electric scooter, giving a real world experience of collaborative work as would be expected from different departments in an industrial environment. Although this seemed a great idea, it was decided that the project was too large for a two semester course because if one of the teams did not meet their objectives, then the whole project would be at risk. Therefore, the project was broken down into three, independent projects, as described below:

1. CNG engine conversion. This project was geared towards students in the Thermo-Fluid and
Propulsion option and the Aerospace and Vehicle Systems option.

2. Lightweight chassis and dynamics study. This project was addressed to students in the Design and Manufacturing option and to the Aerospace and Vehicle Systems option.

3. Regenerative battery electric drive. This project was aimed towards students in the Automation and Control Systems option.

The IE students took up the scooter projects by studying different aspects of industrial engineering. These projects included the following:

1. Market study and product specifications for the scooter.

2. Manufacturing process and technology for the scooter.

3. Ergonomics and Industrial Design for the scooter.

Students were recommended to make use of the textbook by Ulrich and Eppinger [2] to guide them in their work.

\section{Hydroelectric Projects}

Based on an original idea from a previous year's capstone project, the objectives of this project were to design and fabricate a portable hydroelectric power unit to get an electric output of 12 Volts. The component design for this project includes:

1. Intake design.

2. Turbine design.

3. Casing design.

4. Turbine and generator coupling design.

The project was geared towards students in the Thermo-Fluid and Propulsion option and the Design and Manufacturing option.

\section{Student-Defined Projects}

The following four criteria have been set for the student-proposed projects $(20 \%$ of the total projects) to be acceptable:

- The project has to be open-ended.

- There should be sufficient resources in the Department to support the project. This includes machining resources, testing facilities, computing facilities, etc. If a project requires special equipment for testing or special facilities that the Department does not have at the outset, students must demonstrate that they can secure the resources and have sufficient access to assure successful completion of the project. 
- The project should be finished within the time frame of the course, from September to the end of March.

- Each project is allowed a budget of $\$ 500$ for the purchase of materials, supplies, and manufacturing. If students require more than this amount, they must demonstrate that additional funding can be solicited by them to assure successful completion of the project within the time frame.

\section{Team Formation}

For the $80 \%$ of the Department-defined projects, students were organized into teams as follows: each student was asked to submit, in the second week of class, their top three project preferences related to one or both of the products, their option, relevant experience and expertise, interests, and reasons for their selections. Teams were then formed by the CDC by considering these inputs, with an attempt to create teams with complementary skills and interests, and interdisciplinary where possible. The reasoning for having the CDC form the teams was to simulate real industrial environment where people often have to work with team members they do not know; in this way the students can better learn team-building skills and conflict resolution. It was decided that three teams would work on each of the ME projects proposed by the CDC. The rationale for having more teams working on the same project was to bring about competition and difference in originality.

During the summer prior to the start of the fall session, emails were sent out to students registered in the course informing them of the procedure to submit their own proposals for consideration by the CDC. These proposals were evaluated to ensure that the criteria described above were met. Once approved, the students were asked to contact other students with the same interest to form their own teams. Up to $20 \%$ of the projects were determined in this way.

Once the project teams were formed in early September, each team was assigned to a faculty member in their area of specialization. By the end of the second week of the first term, all teams and projects were defined and students were ready to get started on their projects. This approach resulted in a significant improvement in terms of course planning and organizing. The students had to meet their faculty supervisors on a regular basis, whereby the advisor reviewed the project progress by signing the logbook of each individual student. Deliverables and their due dates, as before, were well-defined and provided at the start of the term.

\section{Results}

For the 2004-2005 capstone course, there were twenty ME and five IE capstone projects. With respect to the ME projects, eight teams worked on the scooter project, three teams on the hydroelectric project, five teams on their proposed projects, three on SAE projects, and one on an industry-related project. For the IE students, four teams worked on the scooter project, and one on an industry-related project. The outcome of the new approach was excellent. Out of the twenty ME projects, nineteen teams successfully demonstrated their working prototype. As a further incentive to learn well, to produce a good working prototype, and to have a well-written report and oral presentation, the committee ranked the best two projects for cash prize awards. One prize was established by a retired professor and the second was given from the Department. As well, honourable mentions were awarded to two runner-up ME projects, and another two for IE projects. Figures 1 to 5 show the working prototypes of several ME projects, including CDC proposed projects and student proposed projects.

Figure 1 shows a picture of the hydroelectric turbine project. The water turbine can be seen at the exit of the divergent section of the housing. Handles are built into the housing for easy transport of the hydroelectric unit.

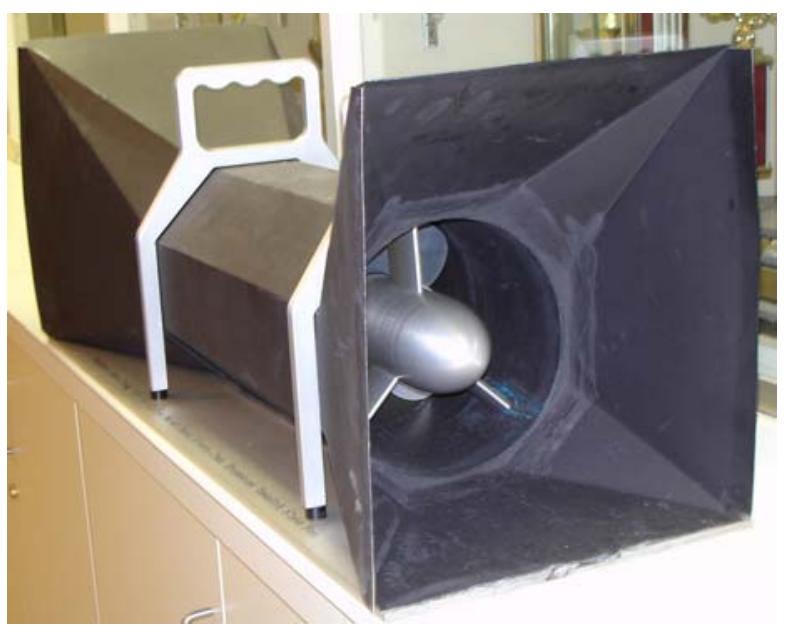

Figure 1. Hydroelectric turbine

Figure 2 shows the battery-operated regenerative braking scooter. The rear wheel is driven by the electric motor/generator through a chain drive. The controller and two batteries are located under the seat storage compartment (cannot be seen). 
Figure 3 shows the original 2-cycle scooter engine converted to burn compressed methane (or CNG). The specially designed pulse width modulation controlled gaseous fuel injector in place of the original carburetor is shown in Figure 3a. This can be seen in the centre of the figure where the pink electrical connector is located. Figure $3 \mathrm{~b}$ shows the complete methane fuelled engine, and Figure $3 \mathrm{c}$ shows the engine mounted on the hydraulically loaded dynamometer for testing.

Figure 4 shows the carbon fibre lightweight scooter frame. An electric motor connected to drive the rear wheel of the scooter is also visible in the figure.

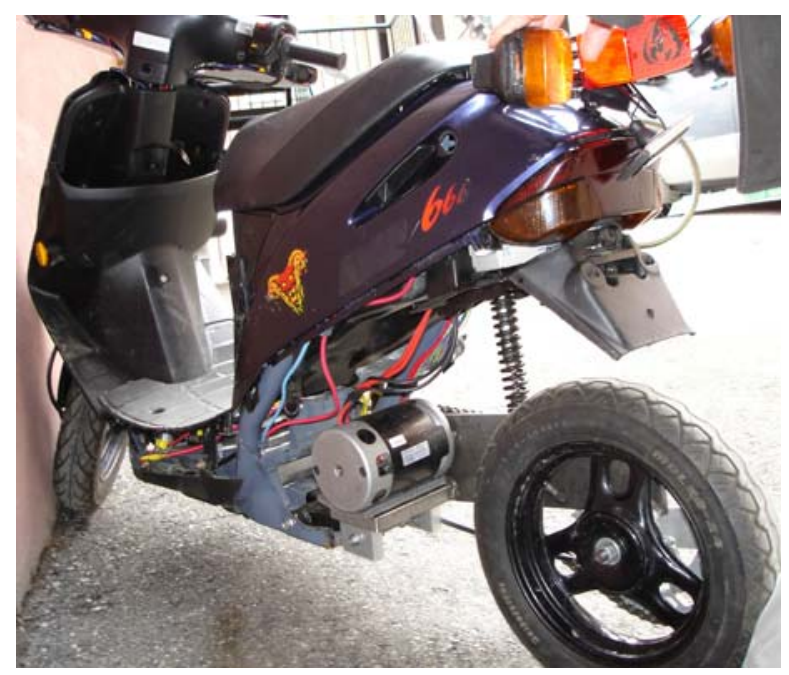

Figure 2. Electric regenerative braking scooter

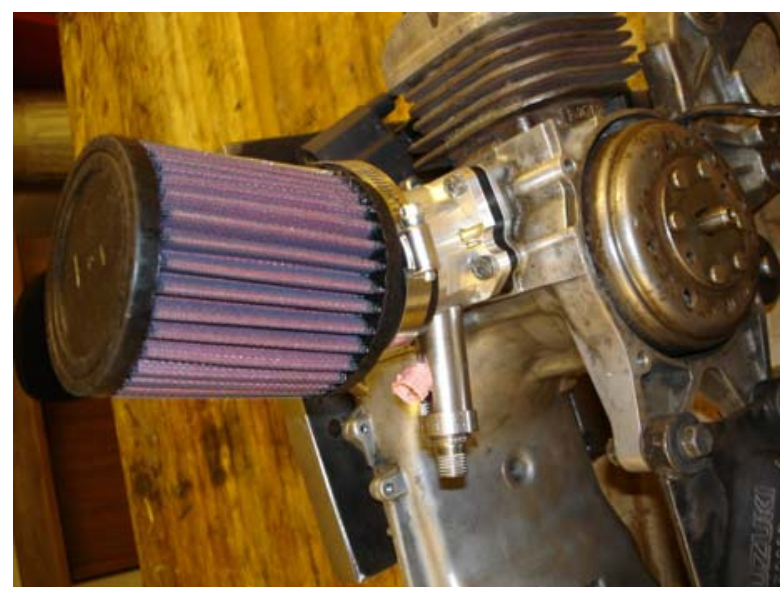

Figure 3a. CNG scooter engine, showing specially designed gaseous injector

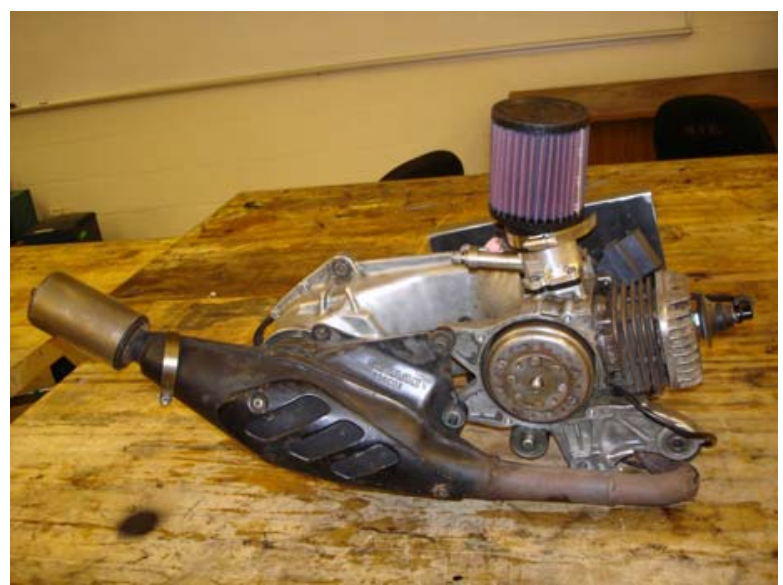

Figure 3b. Complete CNG scooter engine

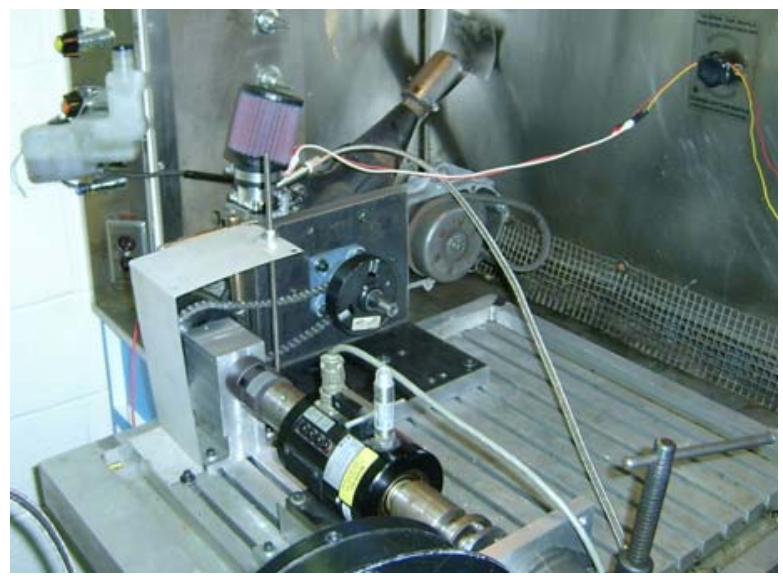

Figure 3c. CNG scooter engine, mounted on hydraulic dynomometer

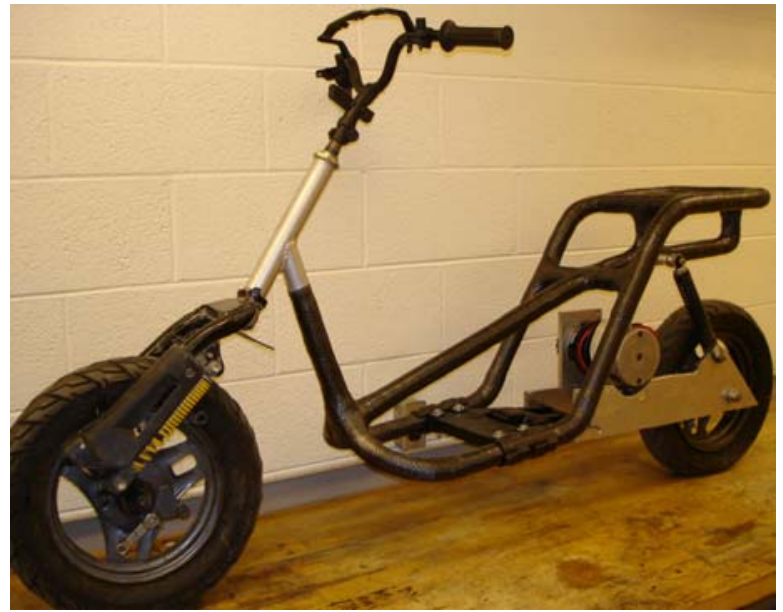

Figure 4. Lightweight carbon fibre scooter chassis 
Figures $5 \mathrm{a}$ and $5 \mathrm{~b}$ show the pictures for the 'NonResonant Suspension Design' project. Although it is desirable for the bicycle rear suspension to compress and absorb the forces from road bumps, the suspension also tends to compress (to resonate, or called the bobbing' effect) when the driver is pedaling. Thus, the objective of the project is to eliminate the 'bobbing' effect which absorbs the driver's pedaling energy. Instead, all the pedaling energy is optimally transferred to more useful work to propel the bicycle.

This was the best year for the capstone teams finishing with working prototypes. Compared to previous years' projects, there has been an increase of over $50 \%$ success rates in this year's projects (i.e., close to $100 \%$ of teams completed the designmanufacture-test-iterate cycle). Besides having a great learning experience, the students commented that the projects, although difficult and time consuming, were actually enjoyable to work on and challenged them with practical engineering designs. The new formula for the course is very successful.

\section{Conclusions}

To ensure that the students learn their engineering profession by practicing it with analytical and handson experience and also to promote excellence in design, the capstone open-ended design project course provides this avenue for success. However, the course structure must be well-controlled and projects must be well-defined in order to ensure a satisfactory learning experience for the complete student spectrum, rather than the self-selected team of top, highly motivated students. To achieve these teaching goals, every professor in the Department is now involved by supervising a capstone team. The defining of the projects originates from the experience of faculty members and their implementation into subprojects are decided and distributed to students by a committee.

To further control the course so that all projects conclude with a working prototype, projects are limited to those approved by the committee. Up to about $20 \%$ of the students are allowed to work on their own proposed projects or industry-related project, after committee approval, whilst the remaining $80 \%$ of students worked on projects defined by the CDC. In addition, for teams to achieve a grade above $\mathrm{B}+$, a prototype must be manufactured and its proper functioning must be demonstrated. The manufacturing of the prototypes does not necessarily have to be carried out in the university machine shop. The machine shop will only manufacture projects for which correct and approved drawings are received by the internal machine shop deadline. If the designs are not submitted by this deadline, these student projects, and those who decided to outsource machining from the outset, have the opportunity to use an external machine shop, but they must remain within their project budget.

The new approach to planning, organizing, and controlling the capstone design course appears to have been very successful this year, and will continue to be improved in coming years.

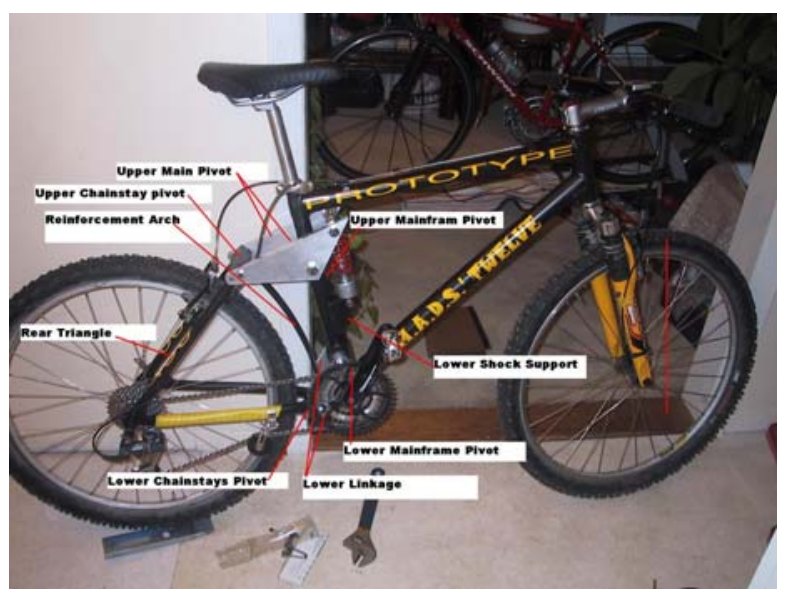

Figure 5a. Non-resonant bicycle suspension

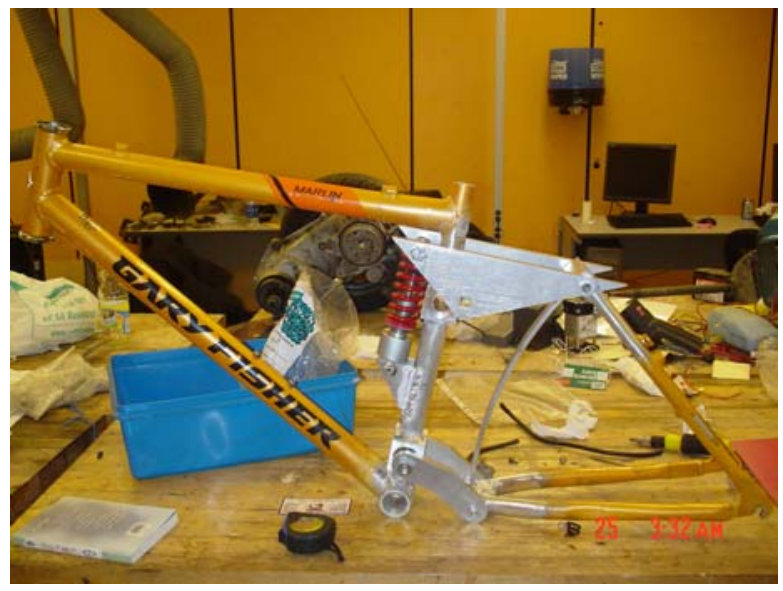

Figure 5b. Non-resonant bicycle frame

\section{References}

[1] Dominick, P.G., Demel, J.T., Lawbaugh, W.M., Freuler, R.J., and Fromm, E., Tools and Tactics of Design, John Wiley \& Sons, 2001.

[2] Ulrich, K. and Eppinger, S., Product Design and Development, 3rd Edition, McGraw-Hill, 2004. 